\title{
COMMENTARY
}

\section{Utile or futile: biomarkers in the ICU}

\author{
Cathrin Balmelli, Beatrice Drexler and Christian Mueller* \\ See related research by Wang et al., http://ccforum.com/content/15/1/R42
}

\begin{abstract}
Biomarkers complement other clinical information by proving quantitative data regarding a pathophysiological mechanism that can be used for the early diagnosis of a specific disease, to monitor and guide treatment, and to predict the risk of death or other adverse events. The stronger the link between the information provided by the biomarker and the immediate clinical course of action that we physicians take in response, the higher the clinical utility of the biomarker. This link is weakest for prognostic biomarkers applied in patients with a wide variety of diseases, such as in unselected intensive care unit (ICU) patients. Although the added value on top of current ICU mortality scores seems to be too low to justify clinical use, the observation that hemodynamic cardiac stress and inflammation are present in multiple conditions provides important insights into the pathophysiology of common disorders in the ICU.
\end{abstract}

In the previous issue of Critical Care, Wang and colleagues [1] present interesting data from a large cohort of unselected medical intensive care unit (ICU) patients which examined the prognostic utility of two wellestablished biomarkers: $\mathrm{N}$-terminal pro-brain natriuretic peptide (NT-proBNP) and C-reactive protein (CRP). In fact, the authors' observations nicely complement the picture that is emerging from several recent studies [1-14]. Like most of the previous studies, their findings leave the majority of ICU physicians in doubt about whether biomarkers are utile or futile.

The ICU is a rather hostile setting for biomarkers. Biomarkers complement other clinical information by proving quantitative data regarding a pathophysiological mechanism that can be used for the early diagnosis of a

*Correspondence: chmueller@uhbs.ch

Department of Internal Medicine, University Hospital, Petersgraben 4, CH - 4031 Basel, Switzerland specific disease, to monitor and guide treatment, and to predict the risk of death or other adverse events. The stronger the link between the information provided by the biomarker and the immediate clinical course of action that we physicians take in response, the higher the clinical utility of the biomarker [13,14].

In most patients finally being admitted to an ICU, the diagnosis is made prior to ICU admission, most commonly in the emergency department (ED). Of course, we still face diagnostic uncertainty in many patients who develop new symptoms or signs during their stay in the ICU (for example, respiratory deterioration or fever). To appropriately examine the diagnostic accuracy of a biomarker in these settings, we need to define a gold standard diagnosis against which the blinded biomarker results are then compared. Unfortunately, owing to, for example, the low specificity of chest $\mathrm{x}$-ray findings, the adjudication of a final diagnosis often is challenging for many common ICU disorders, such as ventilatorassociated pneumonia and hypoxemic respiratory failure $[7,10,12]$. In addition, the extent to which experience and diagnostic cutoff levels can be transferred from studies performed in the ED to the critically ill patients in the ICU is questionable [7,10-14]. Major differences in patient characteristics, disease severity, comorbidity, resources available for the individual patient, and therapies applied between the ICU and the ED require that the potential clinical use of biomarkers in the ICU be defined by specific ICU studies.

What about the utility of biomarkers in monitoring treatment? Biomarkers are used routinely to monitor the efficacy and safety of treatment. For example, urine output and serum creatinine are used to quantify renal function; tidal volumes, oxygen saturation, and arterial partial pressure of oxygen $\left[\mathrm{PaO}_{2}\right]$ are used to tailor ventilator settings; and body temperature, CRP, and procalcitonin are used to assess the response to antibiotics. Although the use of biomarkers in many of these indications is mainly empirical and only partly supported by large prospective studies, it is perceived by most clinicians as utile as the links between the biomarker information and therapeutic consequences are strong [11].

The case is more challenging for prognostic biomarkers. The link to a specific consequence is weakest for 
prognostic biomarkers applied in patients with a wide variety of diseases, such as in unselected ICU patients. The added value of most, if not all, previously examined biomarkers on top of current ICU mortality scores seems to be too low to justify clinical use [1-6]. The prognostic accuracy for ICU or in-hospital death of most biomarkers is modest and inferior to that provided by, for example, the APACHE (Acute Physiology and Chronic Health Evaluation) score [1-7]. This observation seems to be well explained by the wide range of disorders leading to ICU admission and the fact that different organ systems may be the most severely damaged and therefore critical for survival. Moreover, it is important to highlight that there is no perceived unmet clinical need to appropriately riskstratify most patients in the ICU. Simple clinical variables, many of which are captured in the ICU scores, provide immediate and reasonable risk prediction. As cardiovascular function is the key variable in many critically ill patients, BNP and NT-proBNP - as quantitative markers of hemodynamic cardiac stress and heart failure summarizing the extent of systolic and diastolic left ventricular dysfunction, valvular dysfunction, and right ventricular dysfunction - have been shown to be predictors of death in several previous studies. We are still searching how to best apply this information in the clinical care of critically ill patients.

However, prognostic biomarker studies, particularly with BNP and NT-proBNP, have already contributed to a better understanding of many disorders in the ICU. In fact, the observation that hemodynamic cardiac stress is present in multiple conditions provided important novel insights into pathophysiology and highlighted a dominant role of the cardiovascular system of many common disorders in the ICU, including septic shock and weaning failure $[8,9,12]$. Ultimately, these insights will contribute to improvements in our management of ICU patients.

\section{Abbreviations}

BNP, brain natriuretic peptide; CRP, C-reactive protein; ED, emergency department; ICU, intensive care unit; NT-proBNP, N-terminal pro-brain natriuretic peptide.

\section{Competing interests}

CM was supported by research grants from the Swiss National Science Foundation, the Swiss Heart Foundation, Abbott (Abbott Park, IL, USA), Biosite (San Diego, CA, USA), Brahms (Hennigsdorf, Germany), Roche (Basel, Switzerland), Siemens (Munich, Germany), Nanosphere (Northbrook, IL, USA), and the University of Basel. The other authors declare that they have no competing interests.

Published: 9 March 2011

\section{References}

1. Wang F, Pan W, Pan S, Wang S, Ge Q, Ge J: Usefulness of N-terminal pro-brain natriuretic peptide and C-reactive protein to predict ICU mortality in unselected medical ICU patients: a prospective observational study. Crit Care 2011, 15:R42.

2. Januzzi JL, Morss A, Tung R, Pino R, Fifer MA, Thompson BT, Lee-Lewandrowski $\mathrm{E}$ : Natriuretic peptide testing for the evaluation of critically ill patients with shock in the intensive care unit: a prospective cohort study. Crit Care 2006, 10:R37.

3. Roch A, Allardet-Servent J, Michelet P, Oddoze C, Forel JM, Barrau K, Loundou A, Perrin G, Auffray JP, Portugal H, Papazian L: NH2 terminal pro-brain natriuretic peptide plasma level as an early marker of prognosis and cardiac dysfunction in septic shock patients. Crit Care Med 2005, 33:1001-1007.

4. Varpula M, Pulkki K, Karlsson S, Ruokonen E, Pettila V: Predictive value of $\mathrm{N}$-terminal pro-brain natriuretic peptide in severe sepsis and septic shock. Crit Care Med 2007, 35:1277-1283.

5. Shah KB, Nolan MM, Rao K, Wang DJ, Christenson RH, Shanholtz CB, Mehra MR, Gottlieb SS: The characteristics and prognostic importance of NT-ProBNP concentrations in critically ill patients. Am J Med 2007, 120:1071-1077.

6. McLean AS, Tang B, Nalos M, Huang SJ, Stewart DE: Increased B-type natriuretic peptide (BNP) level is a strong predictor for cardiac dysfunction in intensive care unit patients. Anaesth Intensive Care 2003, 31:21-27.

7. Karmpaliotis D, Kirtane AJ, Ruisi CP, Polonsky T, Malhotra A, Talmor D, Kosmidou I, Jarolim P, de Lemos JA, Sabatine MS, Gibson CM, Morrow D: Diagnostic and prognostic utility of brain natriuretic peptide in subjects admitted to the ICU with hypoxic respiratory failure due to noncardiogenic and cardiogenic pulmonary edema. Chest 2007, 131:964-971.

8. Mekontso-Dessap A, de Prost N, Girou E, Braconnier F, Lemaire F, BrunBuisson C, Brochard L: B-type natriuretic peptide and weaning from mechanical ventilation. Intensive Care Med 2006, 32:1529-1536.

9. Grasso S, Leone A, De Michele M, Anaclerio R, Cafarelli A, Ancona G, Stripoli T, Bruno F, Pugliese P, Dambrosio M, Dalfino L, Di Serio F, Fiore T: Use of $\mathrm{N}$-terminal pro-brain natriuretic peptide to detect acute cardiac dysfunction during weaning failure in difficult-to-wean patients with chronic obstructive pulmonary disease. Crit Care Med 2007, 35:96-105.

10. Jefic D, Lee JW, Jefic D, Savoy-Moore RT, Rosman HS: Utility of B-type natriuretic peptide and $\mathrm{N}$-terminal pro $\mathrm{B}$-type natriuretic peptide in evaluation of respiratory failure in critically ill patients. Chest 2005 , 128:288-295.

11. Mueller C, Müller B, Perruchoud AP: Biomarkers: past, present, and future. Swiss Med Wkly 2008, 138:225-229.

12. Noveanu M, Pargger $H$, Breidthardt T, Reichlin T, Schindler C, Heise A, Schoenenberger R, Manndorf P, Siegemund M, Mebazza A, Marsch S, Mueller $\mathrm{C}$ : Use of B-type natriuretic peptide in the management of hypoxaemic respiratory failure. Eur J Heart Fail 2011, 13:154-162.

13. Maisel A, Mueller C, Adams K, Anker SD, Aspromonte N, Cleland JGF, CohenSolal A, Dahlstrom U, DeMaria A, Di Somma S, Filippatos GS, Fonarow GC, Jourdain P, Komajda M, Liu PP, McDonagh T, McDonald K, Mebazza A, Nieminen MS, Peacock WF, Tubaro M, Valle R, Vanderhayden M, Yancy CW, Zannad F, Braunwald E: State of the art: using natriuretic peptide levels in clinical practice. Eur J Heart Fail 2008, 10:824-839.

14. Mueller C, Scholer A, Laule-Kilian K, Martina B, Schindler C, Buser P, Pfisterer M, Perruchoud AP: Use of B-type natriuretic peptide in the evaluation and management of acute dyspnea. N Engl J Med 2004, 350:647-654

doi:10.1186/cc10056

Cite this article as: Balmelli C, et al:: Utile or futile: biomarkers in the ICU. Critical Care 2011, 15:131. 